\title{
Importância da Valva da Veia Ilíaca
}

\author{
Gomes OM. ${ }^{1}$ \\ ${ }^{1}$ Belo Horizonte - Brasil. \\ E-mail: gomes@servcor.com
}

As varizes de membros inferiores constituem uma das mais comuns doenças circulatórias, contudo, até onde foi possível alcançar, não foram encontradas na literatura médica publicações científicas descrevendo a incidência comparativa de regurgitação valvar em veias ilíacas e a gravidade das varizes de membros inferiores.

Considerando a morfologia diferenciada da valva ilíaca, com freqüência exibindo constituição tricúspide, estudamos com exames Duplex Scanning com técnica bidimensional, doppler pulsado e fluxo a cores a ocorrência e intensidade de regurgitação valvar em veias ilíacas estabelecendo como limite de normalidade o refluxo com velocidade de $26,0 \mathrm{~cm} / \mathrm{s}$ e comparando as variações com a intensidade das varizes em membros inferiores. Os resultados obtidos definiram correlação significante entre o aumento do refluxo valvar ilíaco e a gravidade das varizes bem como de suas complicações. Atualmente, considerando essas evidência podemos admitir que o uso terapêutico e/ou preventivo de meias elásticas pressupõe efeitos mais benéficos das meias longas tipo 7/8" ou calça.

Constituem novas fronteiras importantes para a compreensão, prevenção e tratamento da doença doença de regurgitação valvar ilíaca os estudos de incidência na população, em diferentes sexos e grupos etários, bem como de biopróteses e técnicas de valvoplastia.

Palavras chaves: Varizes, Insuficiência Venosa; Veia llíaca. 